\title{
Utilizando uma balança digital de baixo custo como densímetro e sua aplicação a sólidos e líquidos
}

Using a digital scale as a densimeter and its application for solids and liquids

\author{
Wenderson R. F. Silva ${ }^{1 @}$, Jakson M. Fonseca*1@ \\ ${ }^{1}$ Universidade Federal de Viçosa, Departamento de Física, 36570-900, Viçosa, MG, Brasil.
}

Recebido em 26 de agosto de 2020. Revisado em 06 de novembro de 2020. Aceito em 18 de novembro de 2020.

\begin{abstract}
Neste trabalho mostramos como uma balança digital de baixo custo e alguns aparatos simples como, béquer, suporte, arames, cordão, saco plástico e água podem ser utilizados para se medir a densidade de sólidos e líquidos. A montagem proposta pode ser feita de maneira simples, rápida e barata. Os princípios físicos utilizados e as equações matemáticas envolvidas são apresentados de forma simples e didática, o que possibilita a aplicação das ideias apresentadas em ambientes diversos como salas de aula, laboratórios de ensino ou mesmo em casa. Apesar da simplicidade, a precisão e a exatidão das medições não são perdidas. Como exemplo ilustramos seu uso na determinação da densidade de diversos materiais.
\end{abstract}

Palavras-chave: Densímetro, Densidade, Empuxo, Laboratório de Física, Ensino de Física.

In this work we show how a low cost digital scale and some simple devices such as beaker, support, wires, cord, plastic bag and water can be used to measure the density of solids and liquids. The proposed mounting can be done simply, quickly and cheaply. The physical principles used and the mathematical equations involved are presented in a simple and didactic way, what makes it possible to use the ideas presented in different environments such as classrooms, teaching laboratories or even at home. Despite the simplicity, the precision and accuracy of the measurements are not lost. As an example, we illustrate its use in determining the density of various materials. Keywords: Densimeter, Density, Buoyancy, Physics Laboratory, Physics Teaching.

\section{Introdução}

A densidade é uma propriedade física que, por definição, relaciona a massa (quantidade de matéria) de uma substância com o volume ocupado por ela. Os objetos ou corpos são constituídos de matéria e ocupam um volume no espaço, logo, a eles está associada uma densidade, cujo valor é próprio, independente da forma ou tamanho e ajuda na identificação e caracterização desses materiais [1. Muitas vezes os valores das densidades são apresentados como tabelados, sendo propriedades conhecidas dos materiais, o que acaba por mascarar ou mesmo impossibilitar o desenvolvimento de um senso crítico sobre como se medi-la para diferentes materiais como sólidos, líquidos e gases.

Um densímetro é um aparelho que mede a densidade dos materiais, sejam eles sólidos, líquidos ou gases. Os medidores podem ter diferentes princípios de funcionamento, desde os mais simples, como os semelhantes a termômetros de bulbo, comumente encontrados em postos de combustível nas bombas de etanol 2], onde o valor da densidade pode ser obtido por meio da altura da haste do equipamento imerso no fluido, que contém uma escala proveniente de uma calibração previa [3], ou até aqueles mais sofisticados, que utilizam partículas

\footnotetext{
*Endereço de correspondência: jakson.fonseca@ufv.br
}

radioativas e detectores Geiger ou de cintilação para contagem dessas partículas após a passagem pelo material considerado [4, bem como os que estimam a densidade por meio de ultrassom, utilizando o tempo gasto no percurso de travessia ou queda na intensidade do sinal ao propagar pelo material, correlacionando-o com sua densidade [5]. Um instrumento para medidas de densidade alternativo e de fácil montagem pode ser conseguido utilizando-se um tubo em U como mostrando por Gomes et al. [6], entretanto, as medições utilizando esse tipo de equipamento ficam restritas a substâncias líquidas.

Balanças digitais de precisão podem ser preparadas para realizar medidas de densidade [7, entretanto, tais equipamentos apresentam custo elevado, o que muitas vezes impede sua aquisição. Tais balanças, comumente encontradas em estabelecimentos comerciais medem, na verdade, a força com que elas são comprimidas, denominada força normal, e convertem a leitura em valores de massa equivalente, considerando a gravidade padrão, $g=9,81 \mathrm{~m} / \mathrm{s}^{2}[8]$. No caso em que o corpo está imerso no ar há também a força que o ar exerce sobre o corpo, denominada de força de empuxo, porém, para corpos com dimensão reduzida (como os aqui analisados) e devido a baixa densidade do ar, tal força terá uma magnitude muito pequeno (valores inferiores a $1 \%$ ) em 
relação ao peso desses corpos ${ }^{1}$

Aqui será apresentado uma forma de se utilizar uma balança digital de baixo custo em medidas de densidades, de substâncias sólidas e líquidas. Foram deduzidas três equações para o cálculo da densidade dos materiais envolvidos, o que possibilitou medir a densidade de substâncias mais e menos densas que o do líquido de referência, aqui a água destilada. Por meio de um simples saco plástico de espessura fina, podese medir a densidade de líquidos, o que abriu o leque de possibilidade de medidas do aparelho. Descreveremos de maneira simples a teoria e equações utilizadas, bem como os detalhes da montagem, a fim de que qualquer leitor possa reproduzir, sem dificuldades, a medida da densidade de qualquer objeto.

\section{Material e Métodos}

O princípio de Arquimedes estabelece que qualquer corpo imerso em um fluido fica sujeito a uma força vertical, de baixo para cima cujo módulo é igual ao peso do fluido deslocado [1]. Usaremos este importante princípio físico para determinarmos a densidade de corpos utilizando uma balança digital. Começaremos obtendo as equações necessárias, com o auxílio do princípio de Arquimedes. Matematicamente, a força de empuxo pode ser expressa como:

$$
E=\rho \cdot g \cdot V,
$$

onde $E$ é a força denominada força de empuxo, gerada sobre um corpo quando ele desloca um volume $V$ de fluido com densidade $\rho$, imersos em um campo gravitacional $g$. A magnitude de $E$ depende da densidade do fluido deslocado e fica claro que um mesmo corpo pode estar submetido a diferentes valores de $E$, caso seja imerso em diferentes fluidos. Para facilitar a análise vamos considerar três casos distintos separadamente.

\subsection{Sólidos e líquidos mais densos que a água}

Para se medir a densidade precisaremos considerar um fluido de referência, que consideraremos como sendo água, porém pode ser utilizado qualquer outro fluido de densidade conhecida. A Figura 1 abaixo representa o esquema da montagem adotado para se medir a densidade de sólidos e líquidos mais densos que a água (fluido de referência). Quando um objeto feito de material mais denso que a água é colocado em um recipiente contendo água ele afunda devido ao fato do peso do

\footnotetext{
${ }^{1}$ A força de empuxo é uma força vertical, dirigida para cima, que age em qualquer corpo imerso em um fluido, sendo seu módulo igual ao peso do fluido deslocado, ou seja, pode ser calculada multiplicando-se o volume do corpo pela densidade do fluido onde o corpo está imerso pela aceleração da gravidade. Assim é fácil ver que a força de empuxo produzido pelo ar em corpos de dimensão pequena é desprezível em comparação ao seu peso pois a densidade do ar é $1,225 \mathrm{~kg} / \mathrm{m}^{3}$.
}

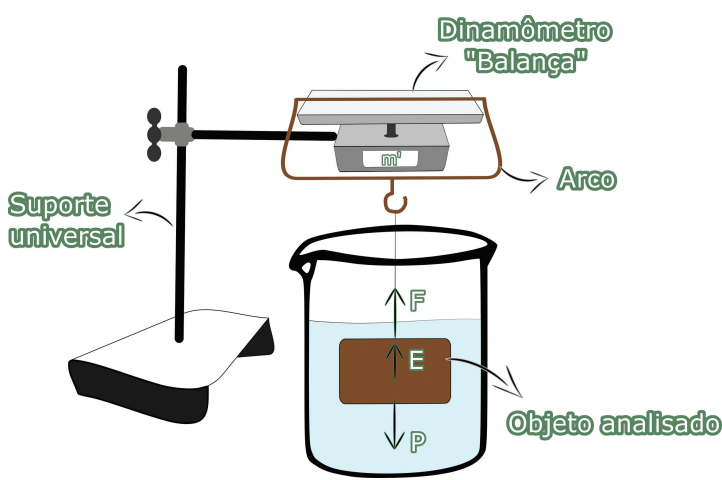

Figura 1: Esquema da montagem experimental proposta para medida de densidades de sólidos e líquidos mais densos que a água e de líquidos menos densos.

objeto (vertical para baixo) possuir módulo maior que a força de empuxo (vertical para cima). Iremos utilizar este fato. Na montagem apresentada na Figura 1 A balança é presa em um suporte e utiliza-se um arco feito de arame para pendurar o objeto. A finalidade do arco é transferir a força que o objeto faz no cordão que o prende para a balança, a qual pode ser lida no mostrador. Importante observar que durante o experimento o objeto fique totalmente imerso na água dentro do béquer. No equilíbrio, a resultante das forças sobre o corpo é igual a zero, com $E$ somado à força $F$ que o cordão exerce sobre o corpo possuirão módulo igual ao peso $P$ do corpo, sendo $F=m^{\prime} \cdot g$, onde $m^{\prime}$ é a massa medida pela balança com o corpo totalmente submerso no fluido que gera a força de empuxo $E$.

Sendo assim, utilizando a condição de equilíbrio do corpo submerso temos:

$$
E+F=P \rightarrow E=P-F=\left(m-m^{\prime}\right) \cdot g .
$$

A força de empuxo sobre o corpo que aparece na Equação (2) também pode ser calculada pela Equação (1). Juntando as expressões (1) e (2), e sendo o líquido gerador da força de empuxo a água destilada, temos:

$$
V=\frac{E}{\rho_{\mathrm{H}_{2} \mathrm{O} \cdot g}}=\frac{\left(m-m^{\prime}\right) \cdot g}{\rho_{\mathrm{H}_{2} \mathrm{O}} \cdot g}=\frac{\left(m-m^{\prime}\right)}{\rho_{\mathrm{H}_{2} \mathrm{O}}},
$$

onde $V$ é o volume de água deslocado pelo corpo que, na situação mostrada na Figura 1 , onde ele está totalmente submerso no fluido, corresponderá ao seu próprio volume. Como $\rho=\frac{m}{V}$, segue que:

$$
\frac{1}{\rho}=\frac{V}{m}=\frac{\left(m-m^{\prime}\right)}{\rho_{H_{2} O} \cdot m},
$$

onde obtemos,

$$
\rho=\frac{m}{\left(m-m^{\prime}\right)} \rho_{H_{2} O} .
$$

Este resultado pode ser usado para a determinação da densidade de qualquer corpo mais denso que a 
água junto com o aparato experimental aqui proposto Figura 1] sendo necessário, determinar, como vê-se da Equação (5), as grandezas envolvidas, $m$ (massa do corpo medida no ar pela balança), $m^{\prime}$ (massa do corpo medida com ele totalmente imerso em água), que podem ser facilmente medidas e a densidade da água utilizada consultada. Utilizou-se água destilada, mas pode-se usar água comum ou qualquer outro fluido de densidade conhecida, lembrando que o resultado (5) se aplica apenas a objetos mais densos que o fluido utilizado. Caso o objeto não afunde no fluido de referência considerado, ele possui uma densidade menor que a do fluido e sua densidade deve ser aferida de outra forma, como discutido posteriormente.

\subsection{Líquidos menos densos que a água}

Para determinarmos a densidade de líquidos menos densos que a água, como óleo de cozinha, por exemplo, pode-se utilizar uma montagem semelhante à da Figura 11. porém trocamos o fluido de referência pelo líquido que queremos determinar a densidade e enchemos um pequeno saco plástico com o líquido de referência, aqui a água destilada. O saco com água fará o papel do sólido imerso no fluido na situação descrita anteriormente. Devido ao plástico possuir pequena massa $(0,05 \mathrm{~g})$ e volume $\left(50 \mathrm{~mm}^{3}\right)$, ele não será considerado nas expressões abaixo ( $E$ da ordem de $0,0005 \mathrm{~N}$ ), sem prejuízos aos resultados. Procedemos então como no caso anterior e deduzimos uma nova expressão como se quiséssemos determinar a densidade do fluido de referência, ou seja, coloca-se o líquido a ser analisado no béquer e a água no saco plástico. Assim, com o saco plástico com água totalmente submerso no fluído, temos, das Equações (1) e 2):

$$
V=\frac{E}{\rho \cdot g}=\frac{\left(m-m^{\prime}\right) \cdot g}{\rho \cdot g}=\frac{\left(m-m^{\prime}\right)}{\rho},
$$

sendo $\rho$ a densidade do líquido a ser determinada e como antes as grandezas envolvidas, $m$ (massa do saco plástico com água medida no ar pela balança), $m^{\prime}$ (massa do saco plástico com água medida com ele totalmente imerso no líquido que deseja-se determinar a densidade) podem ser facilmente medidas. Como $V$ não representa o volume do corpo o qual estamos determinando a densidade e sim o volume da água no saco plástico segue que:

$$
\frac{1}{\rho_{H_{2} O}}=\frac{V}{m}=\frac{\left(m-m^{\prime}\right)}{\rho \cdot m},
$$

onde $m$ é a massa de água medida no ar e $m^{\prime}$ a massa de água medida no fluido de densidade $\rho$. De onde concluímos que:

$$
\rho_{H_{2} O}=\frac{m}{\left(m-m^{\prime}\right)} \rho
$$

e isolando o $\rho$ temos:

$$
\rho=\frac{\left(m-m^{\prime}\right)}{m} \rho_{H_{2} O} .
$$

Assim, pelo mesmo método citado acima, com uma pequena mudança nos fluidos e no arranjo experimental da Figura 1, pode-se medir praticamente fluidos com qualquer densidade, sejam eles com menor ou maior densidade que a do líquido de referência. Para líquidos com densidade maior que a da água podemos manter a água como fluido de referência e colocamos o líquido a ser determinada a densidade no saco plástico e utilizamos a Equação $(5)$ e não a $(9)$.

Outra possibilidade que simplifica muito a análise é utilizar um objeto de densidade conhecida no lugar do saco plástico com água e o líquido cuja densidade que se quer determinar fica dentro do béquer com o corpo imerso e utiliza-se a Equação (9). Neste caso, podese ter um aumento no erro da densidade do líquido, caso a densidade do objeto não seja conhecida com boa precisão. As grandezas envolvidas neste caso, $m$ e $m^{\prime}$, podem ser facilmente medidas e a densidade do corpo utilizado deve ser conhecida e substituída no lugar de $\rho_{\mathrm{H}_{2} \mathrm{O}}$ na Equação (9).

\subsection{Sólidos menos densos que a água}

A terceira situação que iremos considerar é aquela onde queremos determinar a densidade de um sólido menos denso que a água, ou seja, sólidos que flutuam sobre o líquido de referência. A análise se dá por meio de um conjunto de duas equações, retiradas do diagrama de força representado na Figura 2, cujos resultados são apresentados a seguir.

Forças que atuam sobre o corpo:

$$
P=E-F \rightarrow F=E-P .
$$

Considerando o sistema como sendo constituído pelo líquido de referência, o béquer e o corpo cuja densidade queremos determinar, assim sobre o sistema temos:

$$
F+P+P^{\prime}=N \rightarrow F=N-P-P^{\prime},
$$

onde $P$ é o "peso" do corpo medido no ar, $P^{\prime}$ é o peso do béquer e da água juntos sem o objeto e $N$ é a força

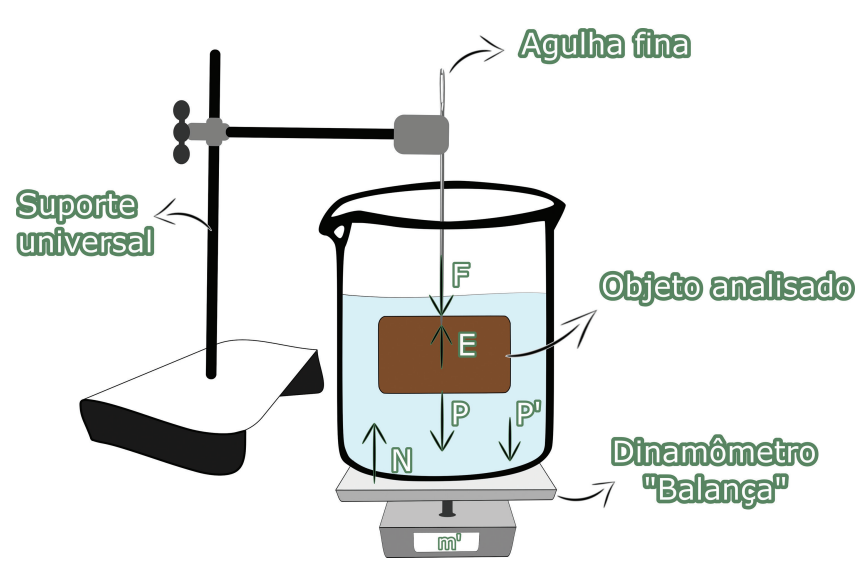

Figura 2: Esquema experimental proposto para medidas da densidade de sólidos menos densos que a água. 
que a balança exerce sobre o sistema quando o objeto está submerso e a força $F$ atuando. Pela terceira lei de Newton sabe-se que a força que o sistema comprime a balança possui mesmo módulo que a força que a balança exerce sobre o sistema, assim a balança registrará $N$. Utilizando as Equações 10 e $(11)$, temos que:

$$
N-P-P^{\prime}=E-P \rightarrow E=N-P^{\prime} \text {. }
$$

Partindo novamente da Equação (1), sendo o líquido gerador da força de empuxo a água, obtemos:

$$
\rho_{\mathrm{H}_{2} \mathrm{O}} \cdot V \cdot g=g \cdot\left(m^{\prime \prime}-m^{\prime}\right),
$$

onde $m^{\prime}$ é a massa associada a $P^{\prime}$ (massa do béquer e da água juntos sem o objeto) e $m^{\prime \prime}$ a massa associada a força $N$ (massa do sistema béquer, água e objeto), medidas pela balança quando o objeto está submerso com a força $F$ atuando, como mostrado na Figura 2. Assim, da Equação (13) obtém-se o volume do corpo:

$$
V=\frac{m^{\prime \prime}-m^{\prime}}{\rho_{\mathrm{H}_{2} O}} \text {. }
$$

Como o volume do corpo $V$ é o mesmo volume deslocado de água quando totalmente submerso, a densidade do corpo $\rho=\frac{m}{V}$ será:

$$
\rho=\frac{m}{m^{\prime \prime}-m^{\prime}} \rho_{H_{2} O},
$$

onde $m$ é a massa do corpo medido no ar. Alguns cuidados devem ser tomados ao se fazer a montagem apresentada na Figura 2 como, por exemplo, o volume de água dentro do béquer tem que ser o mesmo durante todas as medidas, assim o ideal é que o béquer não esteja completamente cheio antes de se imergir o objeto, para que não seja derramado nenhuma quantidade de água.

Como forma de validar o equipamento, será verificado, com auxílio das Equações (5), (9) e (15), a densidade de alguns materiais sólidos e líquidos, bem como uma comparação com os valores apresentados na literatura, quando for o caso.

Buscou-se utilizar de materiais de fácil acesso e de baixo custo, e que possibilitasse precisão nas medidas, sendo eles: uma balança digital da marca Inpelanyu [9], modelo N1124 com precisão de um centésimo de grama; um béquer; um arco feito com fio de cobre encapado; agulha; água destilada (líquido de referência); um termômetro digital com precisão de décimo de grau; linha de costura; sacos de plástico fino (saquinho de geladinho, conhecido também como chup-chup); tesoura; haste universal. Na Figura 3 tem-se a imagem da balança, do arco e do saco plástico com líquido (água) em seu interior.

Os materiais, mostrados na Figura 4, utilizados como amostras para se determinar a densidade foram alguns minerais com geometria irregular: Quartzo, Pirita, Goethita, Hematita, Magnetita e Limonita. No caso de líquidos utilizamos: Glicerina, Álcool Etílico e

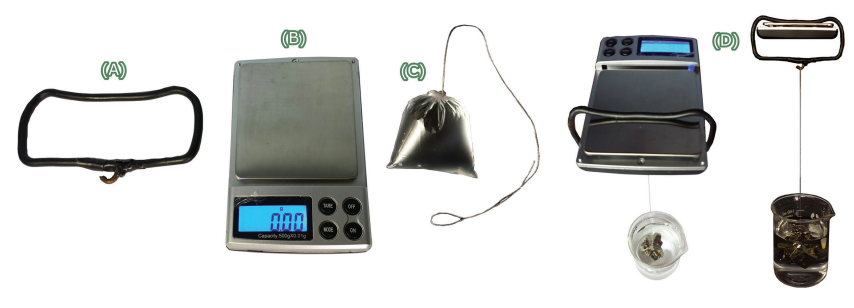

Figura 3: (A) arco, (B) balança, (C) o saco plástico contendo o líquido a ser analisado e em (D) a montagem utilizada no experimento ilustrado pelo esquema da Figura 1 .

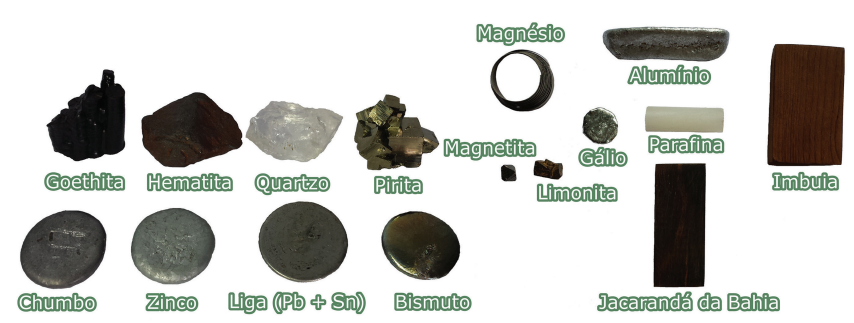

Figura 4: Materiais utilizados como amostras para as medidas de densidade.

Álcool Isopropílico. Utilizamos também materiais vegetais cuja determinação precisa da densidade possui interesse econômico no setor agroindustrial, sendo estes as madeiras: Imbuia e Jacarandá da Bahia. Outros materiais foram a Parafina onde utilizou-se um pedaço de vela sem o pavio e algumas peças de metais como o Chumbo, Zinco, uma liga $(P b+S n)$ que chamaremos de amostra X, Bismuto, Alumínio, Magnésio e o Gálio.

$\mathrm{O}$ experimento foi realizado sobre uma bancada com o equipamento arranjado como mostrado nas Figuras $1 \mathrm{e} 2$ O líquido de referência adotado foi a água destilada e sua temperatura medida no momento de se fazer os experimentos para que o valor mais próximo possível do real para sua densidade fosse utilizado. Consultou-se em tabelas de referências a densidade dos corpos envolvidos e, por meio delas, separou-se os materiais em três grupos; sólidos e líquidos mais densos que a água, líquidos menos densos que a água e sólidos menos densos que a água, grupos estes que se enquadram nas discussões anteriormente apresentadas. Essa análise pode ser feita pelo usuário sem a ajuda de uma tabela, colocando o corpo sobre o líquido de referência e observando se ele afunda ou boia, todavia, para o caso de líquidos miscíveis em água, como o álcool, por exemplo, esse procedimento seria inadequado, podendo ser utilizado um saquinho plástico com o líquido, tomando o cuidado para não armazenar ar.

De acordo com cada modelo e seus respectivos esquemas experimentais aqui apresentados, preparou-se as amostras a serem analisadas. Os mineiras e os metais foram amarrados com a linha de costura e, na outra extremidade da linha, feito um laço, para se fixar no arco. Para os líquidos, colocou-se cerca de $10 \mathrm{ml}$ no 
saco plástico de chup-chup, amarrando-o com a linha de costura, tomando cuidado para que ar não fique preso dentro do saco plástico.

Já para a madeira e a parafina, utilizou-se do esquema da Figura 2, no qual fixou-se a agulha em uma das faces da amostra e a outra extremidade da agulha presa na haste universal por onde pode-se posicionar a amostra dentro do béquer. Para cada uma das amostras, repetiuse o experimento três vezes e registou-se os valores das massas indicadas pela balança nas Tabelas 1 e 2 abaixo. Com o valor médio das massas referentes a cada um dos experimentos, pode-se calcular a densidade dos corpos envolvidos, cujos valores serão apresentados e discutidos na próxima seção.

\section{Resultados e Discussão}

Com base nos modelos discutidos anteriormente, onde chegou-se as Equações (5), (9) e (15) e em seus esquemas experimentais correspondentes, pode-se chegar aos resultados das densidades dos materiais apresentadas na Tabela 1. Importante mencionar que antes de iniciar as medidas das massas a balança foi calibrada no local do experimento, afim de se saber se havia desvios nas medidas em comparação com um equipamento industrial. Os valores estão bem ajustados, dentro da precisão de 0,01 g da balança, e um gráfico do ajuste pode ser visto da Figura M1 no Material suplementar. Como sabese a densidade de qualquer corpo (sólido ou líquido) muda com a temperatura devido a dilatação volumétrica do mesmo. Determinou-se uma expressão polinomial ajustando os valores da densidade da água em função da temperatura, entre 15 e $30^{\circ} \mathrm{C}$, para que se possa obter sua densidade sabendo-se, somente, sua temperatura. A equação resultante é:

$$
\rho_{H_{2} O}=4,780 \times 10^{-6} T^{2}-1,573 \times 10^{-5} T+1,000
$$

onde $T$ é o valor da temperatura da água em graus Celsius e $\rho_{\mathrm{H}_{2} \mathrm{O}}$ é a densidade da água em $\mathrm{g} / \mathrm{cm}^{3}$ [10]. Um gráfico com o ajuste polinomial pode ser visualizado na Figura M2 no Material suplementar. Assim, no momento do experimento, utilizou-se o termômetro digital e aferiu-se a temperatura da água para cada uma das três situações analisadas. A coluna correspondente a EP na Tabela 1 corresponde ao erro padrão, obtido por se considerar três medidas para a mesma massa.

Para se determinar a densidade de uma liga cuja constituição é a combinação de mais de um metal de densidades conhecidas pode-se lançar mão da Equação (17) abaixo, que é uma média ponderada da densidade dos diferentes materiais que compõem a liga:

$$
\frac{1}{\rho}=\frac{\sum V}{\sum m}=\frac{\frac{m_{1}}{\rho_{1}}+\frac{m_{2}}{\rho_{2}}+\cdots+\frac{m_{n}}{\rho_{n}}}{m_{1}+m_{2}+\cdots+m_{n}} .
$$

A amostra X (liga de $\mathrm{Pb}+\mathrm{Sn}$ ) foi extraída de um rolo de solda para eletrônica da marca Best, cujo constituição é de $60 \%$ de Estanho $(S n)$ e $40 \%$ de Chumbo $(P b)$ [1]. Portanto, para esse caso particular, temos:

$$
\begin{aligned}
\frac{1}{\rho_{X}} & =\frac{\sum V}{\sum m}=\frac{\frac{m_{P b}}{\rho_{P b}}+\frac{m_{S n}}{\rho_{S n}}}{m_{P b}+m_{S n}} \\
& =\frac{1}{\rho_{P b}}\left(\frac{m_{P b}}{m_{P b}+m_{S n}}\right)+\frac{1}{\rho_{S n}}\left(\frac{m_{S n}}{m_{P b}+m_{S n}}\right) .
\end{aligned}
$$

As expressões entre parênteses na Equação 18 representam as frações volumétricas de massa envolvidas na amostra X, sendo o primeiro a quantidade de Chumbo e o segundo a quantidade de estanho, ambos em relação a massa total da amostra. Portanto, de acordo com os dados do fabricante da liga utilizada as frações volumétricas de chumbo e estanho são respectivamente $0,40(P b)$ e 0,60 $(S n)$. Conhecendo a densidade desses dois elementos separadamente [9], pode-se determinar a densidade da peça com auxílio da Equação (18), como mostrado a seguir:

$$
\frac{1}{\rho_{X}}=\frac{0,40}{11,34}+\frac{0,60}{7,29} \rightarrow \rho_{X}=8,547 \frac{\mathrm{g}}{\mathrm{cm}^{3}} .
$$

Para o caso de líquidos menos densos que a água, chegaram-se aos resultados apresentados na Tabela 2.

No caso das densidades relacionadas as madeiras, pode-se obter a densidade aparente e a densidade básica. Aqui medimos a densidade aparente das madeiras Jacarandá da Bahia (Dalbergia nigra) e Imbuia (Ocotea porosa), isolando-as com uma película de fita adesiva durex para que não houvesse absorção de água pela amostra, o que afetaria a análise, pois a composição da amostra sendo mudada. A parafina foi obtida de um bastão de vela, o qual foi retirado o pavio. Os resultados estão apresentados na Tabela 3

Para todos os modelos aqui apresentados (Equações (5), (9) e (15)) obteve-se bons resultados, principalmente em relação aos materiais cuja constituição química e pureza são conhecidos com boa precisão (>99\%). O uso de um único instrumento de medida (neste caso a balança) favoreceu tais resultados, diminuindo o erro associado as medidas das massas, uma vez que a incerteza associada aos equipamentos de medidas se restringiu a um único instrumento, cuja precisão é de $0,01 g$ [9]. Outras possíveis fontes de erro em alguns casos fato de desconsiderarmos a densidade do saco plástico utilizado, bem como a possibilidade de alguma quantidade de ar ficar retido no mesmo, porém, isso não invalida os fins didáticos da montagem, desde que esclarecidos estes pontos.

A montagem proposta pode ser empregada também para determinação de volumes de sólidos irregulares, possuindo a vantagem de se obter valores com precisão de duas casas decimais. Pode-se usar outras balanças, bastando apenas reajustar o arco para a forma desejada ou mesmo um dinamômetro pode ser utilizado, porém aumentaria os custos com equipamentos. O saco 
Tabela 1: Valores das grandezas referentes as medidas feitas de acordo com o modelo da Equação (5).

\begin{tabular}{|c|c|c|c|c|c|c|c|c|}
\hline & $\mathrm{m}_{1}$ & $\mathrm{~m}_{1}^{\prime}$ & $\mathrm{m}_{2}$ & $\mathrm{~m}_{2}^{\prime}$ & $\mathrm{m}_{3}$ & $\mathrm{~m}_{3}^{\prime}$ & Densidade & EP \\
\hline Unidade & \multicolumn{6}{|c|}{ (g) } & \multicolumn{2}{|c|}{$\left(\mathrm{g} / \mathrm{cm}^{3}\right)$} \\
\hline Zinco $(99,99 \%)$ & 43,54 & 37,39 & 43,53 & 37,41 & 43,55 & 37,39 & 7,076 & 0,013 \\
\hline Gálio $(99,99 \%)$ & 5,84 & 4,87 & 5,86 & 4,87 & 5,85 & 4,87 & 5,960 & 0,029 \\
\hline Bismuto $(99,99 \%)$ & 49,70 & 44,63 & 49,66 & 44,57 & 49,71 & 44,62 & 9,759 & 0,014 \\
\hline Magnésio (99, & 1,92 & 0,80 & 1,90 & 0,79 & 1,91 & 0,79 & 1,708 & 0,003 \\
\hline Chumbo & 73,38 & 66,74 & 73,38 & 66,77 & 73,38 & 66,77 & 11,07 & 0,017 \\
\hline Cobre (fio) & 20,75 & 18,40 & 20,78 & 18,39 & 20,76 & 18,40 & 8,760 & 0,041 \\
\hline Alumínio & 34,85 & 21,60 & 34,86 & 21,59 & 34,86 & 21,60 & 2,625 & 0,001 \\
\hline Liga $(\mathrm{Sn}+\mathrm{Pb})$ & 57,73 & 51,00 & 57,74 & 50,99 & 57,75 & 50,96 & 8,532 & 0,021 \\
\hline Constantan $(\mathrm{Cu}+\mathrm{Ni})$ & 1,14 & 1,03 & 1,17 & 1,02 & 1,15 & 1,02 & 8,989 & 0,743 \\
\hline Glicerina $(99,5 \%)$ & 17,92 & 3,45 & 17,96 & 3,45 & 17,97 & 3,44 & 1,236 & 0,000 \\
\hline Quartzo & 18,50 & 11,52 & 18,47 & 11,49 & 18,50 & 11,51 & 2,643 & 0,001 \\
\hline irita & 44,10 & 35,13 & 44,14 & 35,13 & 44,18 & 35,14 & 4,893 & 0,008 \\
\hline Limonita & 5,28 & 3,90 & 5,29 & 3,92 & 5,28 & 3,91 & 3,841 & 0,011 \\
\hline Goetita & 37,60 & 28,02 & 37,61 & 28,02 & 37,61 & 28,06 & 3,922 & 0,005 \\
\hline Hematita & 3,28 & 2,64 & 3,29 & 2,66 & 3,27 & 2,66 & 5,228 & 0,068 \\
\hline Magnetíta & 2,36 & 1,93 & 2,37 & 1,92 & 2,37 & 1,92 & 5,332 & 0,074 \\
\hline
\end{tabular}

Tabela 2: Valores das grandezas referentes as medidas feitas de acordo com o modelo da Equação (9).

\begin{tabular}{|c|c|c|c|c|c|c|c|c|}
\hline \multirow[b]{2}{*}{ Unidade } & $\mathrm{m}_{1}$ & $\mathrm{~m}_{1}^{\prime}$ & $\mathrm{m}_{2}$ & $\mathrm{~m}_{2}^{\prime}$ & $\mathrm{m}_{3}$ & $\mathrm{~m}_{3}^{\prime}$ & Densidade & $\mathrm{EP}$ \\
\hline & \multicolumn{6}{|c|}{ (g) } & \multicolumn{2}{|c|}{$\left(\mathrm{g} / \mathrm{cm}^{3}\right)$} \\
\hline Álcool $(99,5 \%)$ & 13,76 & 2,88 & 13,76 & 2,89 & 13,83 & 2,96 & 0,7876 & 0,0015 \\
\hline Acetona & 18,97 & 3,87 & 18,97 & 3,86 & 18,96 & 3,87 & 0,7949 & 0,0002 \\
\hline Gasolina & 18,97 & 4,48 & 18,95 & 4,44 & 18,96 & 4,51 & 0,7627 & 0,0010 \\
\hline Isopropanol $(99,8 \%)$ & 10,56 & 2,22 & 10,56 & 2,22 & 10,57 & 2,23 & 0,7883 & 0,0002 \\
\hline Óleo de soja & 18,96 & 1,70 & 18,97 & 1,70 & 18,97 & 1,71 & 0,9087 & 0,0002 \\
\hline Querozene & 10,56 & 2,17 & 10,54 & 2,17 & 10,56 & 2,16 & 0,7934 & 0,0004 \\
\hline
\end{tabular}

Tabela 3: Valores das grandezas referentes as medidas feitas de acordo com o modelo da Equação (15).

\begin{tabular}{|c|c|c|c|c|c|c|c|c|c|c|c|}
\hline \multirow[b]{2}{*}{ Unidade } & $\mathrm{m}_{1}$ & $\mathrm{~m}_{1}^{\prime}$ & $\mathrm{m}_{1}^{\prime \prime}$ & $\mathrm{m}_{2}$ & $\mathrm{~m}_{2}^{\prime}$ & $\mathrm{m}_{2}^{\prime \prime}$ & $\mathrm{m}_{3}$ & $\mathrm{~m}_{3}^{\prime}$ & $\mathrm{m}_{3}^{\prime \prime}$ & Densidade & $\mathrm{EP}$ \\
\hline & \multicolumn{9}{|c|}{ (g) } & \multicolumn{2}{|c|}{$\left(\mathrm{g} / \mathrm{cm}^{3}\right)$} \\
\hline Jacarandá & 30,94 & 192,63 & 226,34 & 30,93 & 192,63 & 226,30 & 30,93 & 192,64 & 226,27 & 0,9166 & 0,0005 \\
\hline Imbuía & 38,77 & 192,20 & 251,55 & 38,76 & 192,34 & 251,33 & 38,76 & 192,27 & 251,36 & 0,6539 & 0,0011 \\
\hline Cartiça (rolha) & 1,70 & 97,72 & 104,42 & 1,70 & 97,71 & 104,42 & 1,71 & 97,70 & 104,42 & 0,2533 & 0,0011 \\
\hline Parafina & 8,42 & 191,56 & 200,82 & 8,42 & 191,56 & 200,74 & 8,42 & 191,54 & 200,75 & 0,9115 & 0,0023 \\
\hline
\end{tabular}

plástico de espessura fina utilizado na medida de líquidos mostrou ser apropriado, bem como uma alternativa ao arranjo de difícil montagem que são utilizados junto às balanças destinadas a medidas de densidade, o que facilitou a montagem e abriu o leque de possibilidade de medidas do aparelho. Reiteramos que os bons resultados obtidos na medida da densidade de líquidos dependem da habilidade do experimentador em não deixar ar dentro dos sacos plásticos e em fazer a montagem como descrito anteriormente. A metodologia adotada para obtenção das expressões matemáticas utilizadas no experimento é uma forma de abordar a teoria da hidrostática, trazendo para os alunos uma finalidade prática relacionada aos temas abordados em sala, como a discussão sobre a força de empuxo, densidades relativas e equilíbrio de forças. 


\section{Conclusões}

A caracterização de materiais é um importante passo no conhecimento de suas propriedades e características para serem empregados da melhor forma possível, seja em dispositivos eletrônicos, mecânicos, ou mesmo em uso cotidiano. O conhecimento da densidade dos materiais é um dos primeiros passos nesse processo, que pode ser muito complexo e caro, dependendo do tipo de propriedade que deseja-se caracterizar. Propomos aqui uma maneira de se determinar a densidade de diferentes materiais, sejam eles sólidos ou líquidos utilizando-se uma balança digital, um béquer, um suporte, saquinhos de chup-chup e arames e linhas. Conclui-se que é possível utilizar uma balança de precisão de baixo custo como parte de um densímetro. Por ser simples, de fácil manuseio e simples análise dos dados, pode ser destinado a aulas de física e química, em temas relacionados a densidades de sólidos e líquidos, bem como pode-se discutir conceitos de equilíbrio de corpos submersos, força de empuxo e composição de materiais. Outros aspectos podem ser abordados como a pureza de um material ou a sua composição aferidos por meio de sua densidade.

\section{Agradecimentos}

Os autores expressam seus agradecimentos ao professor Ernesto von Rückert e a professora Erica Toledo de Mendonça pela leitura e comentários sobre o trabalho. Agradecemos também as agências de fomento CAPES (Código de Financiamento 001), CNPq e FAPEMIG pelo apoio financeiro.

\section{Material suplementar}

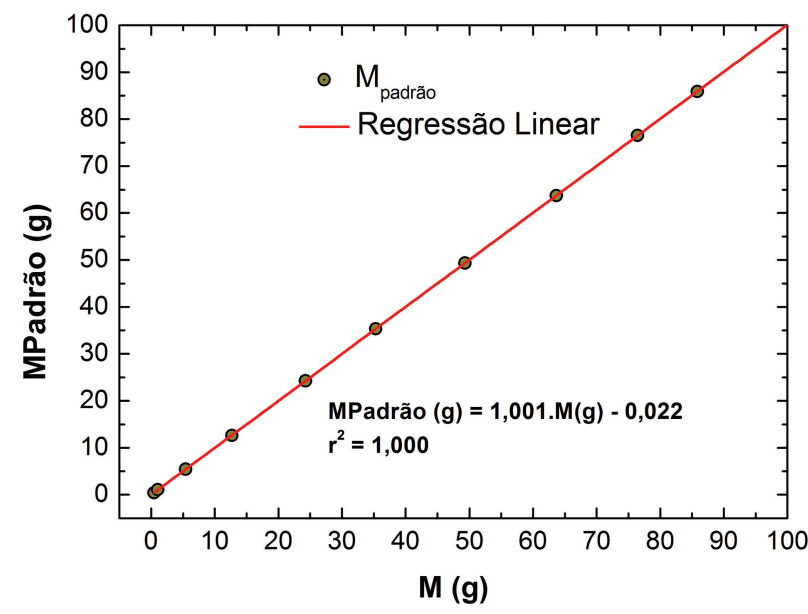

Figura M1: Ajuste obtido medindo-se os valores de massa em uma balança industrial (MPadrão, marca: OHAUS, modelo: TS200S) e na balança utilizada no experimento aqui proposto.

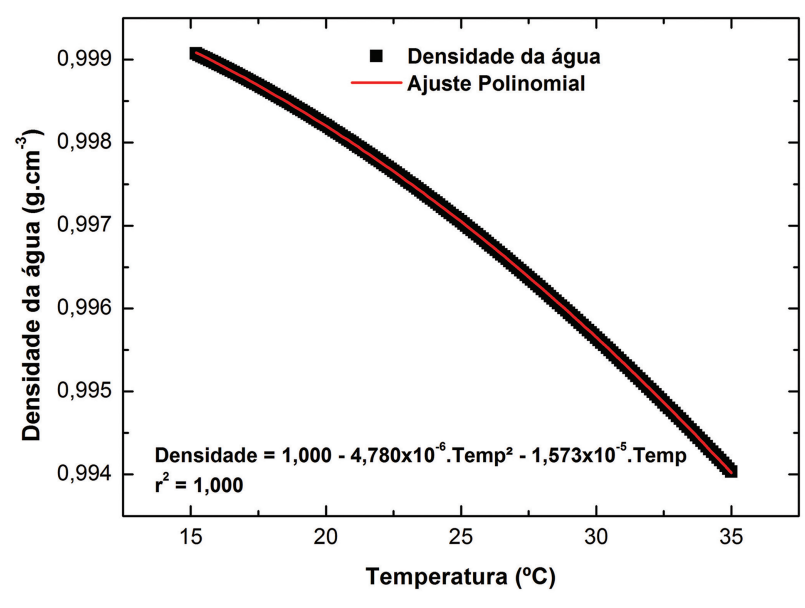

Figura M2: Ajuste polinomial obtido para a densidade da água em função de sua temperatura, com dados retirados da referência [10].

\section{Referências}

[1] H.D Young e R.A. Freedman, Termodinâmica e Ondas (Addison Wesley, São Paulo, 2016), v. 2.

[2] https://bit.ly/3aYZZ7V, acessado em 25/10/2020.

[3] B.M. Oliveira, J.M.M. Filho e C.J. Afonso, Rev. Bras. Ensino Fís. 35, 1 (2013).

[4] I.M. Astafieva1, D.N. Gerasimov e R.E. Makseev, J. Phys: Conf. Series. 891, 012322 (2017).

[5] A. Puttmer, P. Hauptmann e B. Henning, IEEE Transactions on Ultrasonics Ferroelectrics and Frequency Control. 47, 1 (2000).

[6] A.V. Gomes, E.M.S. Amaral e R.J. Prado, Rev. Bras. Ensino Fís. 41, 3 (2019).

[7] https://bit.ly/2C5A0wv, acessado em 25/10/2020.

[8] https://bit.ly/2WnCtMM, acessado em 25/10/2020.

[9] Inpelanyu, Manual balança INPELANYU-N1124, $500 \mathrm{~g}-0.01 \mathrm{~g}$ (China, 2018).

[10] D. R. Lide, Handbook of Chemistry and Physics (CRC Press, New York, 2009).

[11] https://bit.ly/2WqvsKY, acessado em 25/10/2020. 